\title{
ПРАКТИКА ПРИМЕНЕНИЯ ЦИФРОВЫХ ТЕХНОЛОГИЙ В ПРОЦЕССЕ ВНУТРИФИРМЕННОГО ОБУЧЕНИЯ СПЕЦИАЛИСТОВ В ОБЛАСТИ УПРАВЛЕНИЯ ПЕРСОНАЛОМ
}

\section{THE PRACTICE OF USING DIGITAL TECHNOLOGIES IN THE PROCESS OF IN-HOUSE TRAINING OF SPECIALISTS IN THE FIELD OF PERSONNEL MANAGEMENT}

\section{Zuev}

Summary: This article discusses the problems of using digital technologies in the process of in-house training of specialists in the field of personnel management; the author's definition of a distance educational environment is given, in which training is carried out using digital technologies in the process of in-house training of specialists in the field of personnel management; presents the training opportunities with the productive use of the Internet, the correct sorting of information, the selection of essential and insignificant factors in its significance; a structural and functional model of remote communication using digital technologies is proposed.

Keywords: digital technologies, personnel management, remote communication, distance learning environment, in-house training.

\author{
Зуев Иван Анатольевич \\ аспирант, ФГБОУ ВО «Ивановский государственный \\ университет» (Шуйский филиал), г. Иваново \\ ivanzuev2010@mail.ru
}

Аннотация: В данной статье рассмотрены проблемы применения цифровых технологий в процессе внутрифирменного обучения специалистов в области управления персоналом; приводится авторское определение дистанционной образовательной средой, в которой и проводится обучение с применением цифровых технологий в процессе внутрифирменного обучения специалистов в области управления персоналом; представлены возможности обучения с продуктивным использованием Интернета, правильному сортированию информации, выделению существенных и несущественных факторов в ее значимости; предложена структурно-функциональная модель осуществления удаленной коммуникации с применением цифровых технологий.

Ключевые слова: цифровые технологии, управление персоналом, удаленная коммуникация, дистанционная образовательная среда, внутрифирменное обучение.
$\mathrm{H}$ а привлечение научной мысли к использованию информационных технологий для повышения эффективности обучения повлияли глобальные изменения в науке, технике, социуме и экономике. Они стали причиной увеличения степени информатизации в обществе, способствовали распространению информационных коммуникаций в социальной жизни и созданию удаленных образовательных пространств.

Актуальность темы статьи определяется тем, что при обучении специалистов в области управления персоналом использование информационных технологий, компьютерной и организационной техники, различных образовательных сервисов и телекоммуникационных систем обусловлено характером и интенсивностью процессов информатизации, происходящих в социуме, в образовательном пространстве, которое в условиях пандемии формируется, как совокупность образовательных учреждений всех типов, взаимодействующих друг с другом, с иными государственными, общественными учреждениями, организациями, в которых поддерживаются и организуются учебно-воспитательные и образовательные процессы на всех уровнях получения образования, а также индивидуальных цифровых средств обучащих для групповой и индивидуальной работы. Однако, пока единого понимания, что должно представлять собой внутрифирменное обучение специалистов в области управления персоналом с применением цифровых технологий, нет ни в научных кругах, ни у тех кто непосредственно организует и проводит такое обучение.

В нашем представлении, обучения специалистов с применением цифровых технологий в области управления персоналом - это совокупность межличностных и деловых отношений по следующим типам: «обучаемый - обучающий - обучаемый», «обучаемый - обучаемый». Их особенностью становятся удаленность в пространстве и во времени. В таком случае необходимо отметить, что образовательная реальность становится относительно реальной формой существования, а ее основным элементом - социально-виртуальная реальность. Взаимоотношения субъектов не имеют иерархической организацию в системе, но формируются в причудливые сочетания. Анализ процесса обучения с точки зрения социального взаимодействия показывает содействие и совместную деятельность, которые объединяют обучающихся и обучаемых в рамках общей проблемы, решаемых задач [8, с. 138]. 
Дистанционная форма обучения раскрывает и творческие способности обучаемых обучения специалистов в области управления персоналом. Она должна способствовать эффективному усвоению учебных материалов, продуктивному взаимному обмену информацией между дистанционным обучаемым и обучающимися, решать ориентированные на практику задачи в выбранном предметном цикле. Подобная форма организации обучения привлекает обучаемого в процесс познания, активизацию потенциала, его творческих возможностей и способностей. Обучаемым в дистанционном режиме оказывается необходимая консультационная помощь с использованием цифровых образовательных ресурсов, учебных материалов, также в случае обсуждения достижений в ходе промежуточных аттестаций.

Консультации, тестирование, обсуждение итогов обучения в удаленной форме обучения не являются приоритетными. Процесс осознания может осуществляться в виртуальных аудиториях, в виде чатов, на интерактивных досках, в форумах. При отсутствии обратной связи, по мнению А.А. Андреева, В.И. Солдаткина [3], Д.3. Ахметовой [4], становится невозможной организация содержательного и продуктивного процесса обучения.

Авторы сходятся во мнении, что эффективное дистанционное обучение определяется следующими аспектами: а) разноплановым взаимодействием между обучающим и обучаемым; б) наличием обратной связи в информационно-образовательно среде; в) адекватным и полноценным использованием педагогических технологий с учетом особенностей каждого обучаемого; г) качеством предоставляемых методических и информационных материалов; д) систематическим контролем за процессом обучения, его организацией и результатами каждого удаленного обучаемого; е) организацией итоговой аттестации.

Обучение с использованием цифровых технологий и есть составная часть дистанционного (электронного) образования в современном его понимании.

Информатизация образования - это ступень к переходу к цифровой образовательной среде, в которой обучение проводится дистанционно с применением цифровых образовательных технологий.

Под дистанционной образовательной средой, в которой и проводится дистанционное обучение, будем понимать интеграцию результата взаимодействия преподавателя, обучаемым и информационных каналов в единый и целостный процесс, направленный на овладение знанием, умением и опытом в масштабе тех задач, которые стоят перед субъектами образовательного процесса. То есть, по нашему мнению, обучение с использованием цифровых технологий следует считать лишь составной частью дистанционного (электронного) образования в современном его понимании.

Процесс внутрифирменного обучения специалистов в области управления персоналом нами соотносится с работой таких категорий обучающих, как тренеры, инструкторы и другие специалисты в сфере работы с персоналом.

В образовательной сфере вектор научного развития проблемы применения цифровых технологий в процессе обучения был задан еще полтора десятиления назад в докторской диссертации А.О. Чефрановой [14] и нашел свое развитие в последующих научных трудах таких ученых, как А.Л. Абрамовский [1], А.А. Скворцов [9], И.Н. Теркулова [12] и др.

Предпосылками успеха становления цифровой экономики со стороны образовательного сообщества постепенно становилось стремление, умение и изыскание возможностей построения новых моделей обучения, основанных на технологично организованной работе с будущим - это воплощается в стратегиях образовательных организаций и в разработке механизма оперативной сценарной подстройки стратегии системы образования к параметрам турбулентной внешней среды (например, пандемии коронавируса 2020-2021 гг.).

Представляется, что цифровые технологии постепенно приведут к трансформации всей системы образования, поэтому главной составляющей структуры образования при переходе ее в новое качественное состояние, когда цифровые технологии доминируют во всех ее сферах, является стратегия по взаимодействию образовательного процесса с цифровыми технологиями.

Для организации обучения специалистов в области управления персоналом именно средства информационных технологий помогают обучающего эффективно взаимодействовать с обучаемыми.

Одним из преимуществ применения инновационных средств в удаленном учебном процессе становится выбор и предпочтения по взаимодействию обучаемого с цифровым продуктом, где уровень активности пользователя в рамках дистанционного обучения является показателем качества по предметному циклу.

Как указывает ряд авторов [2; 6; 7], интернет-урок (занятие) в рамках дистанционного обучения предполагает выход за рамки стандартного учебного процесса, поскольку рассчитан на использование компьютерных технологий и средств, увеличивающих образовательные возможности субъектов, позволяющих приобрести необходимые умения, навыки и опыт деятельности в рамках распределенной удаленной деятельности, спо- 
собствующих осуществлению выбора и реализации собственной индивидуальной образовательной траектории в системе интернет-пространства. Подобный вид занятия направлен на обучение продуктивному использованию возможностей Интернет, правильному сортированию информации, выделению существенных и несущественных факторов в ее значимости.

Вебинар - это форма организации дистанционного обучения, представляющая собой обучение в режиме онлайн. Он похож, в некоторой степени, на семинар, на котором представляются последовательно доклады, показываются демонстрации, задаются вопросы, предлагаются ответы, однако все действия происходит в режиме реального времени и передается через Интернет.

Мастер-класс является современным и оригинальной формой обучения, которая представляет собой конкретное занятие, показывающее совершенствование практического мастерства и проводимое тем или иным специалистом в определенной области деятельности для индивидов, которые уже достигли достаточного уровня мастерства в выбранной сфере деятельности.

Практикум - это особая форма учебных занятий, основной задачей которых становится практическое усвоение фундаментальных положений преподаваемого предмета. В практикуме могут содержаться практические занятия по учебному модулю или курсу.

Видеоконференция - это технология интерактивного взаимодействия двух и более удаленных участников с помощью видео и микрофона, при которой между ними возможен обмен информацией в реальном времени.

Средствами дистанционного обучения в описываемой структурно-функциональной модели являются технико-методические средства. К техническим относятся: компьютер, Интернет, видеокамера, микрофон, ПО «Скайп», наушники. Данные средства обеспечивают фактическое присоединение к сети-Интернет и помогают осуществлять удаленную коммуникацию.

Что касается процесса цифровизации внутрифирменного обучения специалистов в области управления персоналом, то он находился практически на начальном этапе. Несмотря на определенную оснащенность обучающих оборудованием, цифровые технологии до коронокризиса использовались в учебном процессе не очень активно. Поэтому экстренная цифровая трансформация, которая хоть и медленно, но происходила в контексте системы образования, в условиях пандемии получила серьезное ускорение: в короткое время на вынужденное дистанционное обучение перешли многие участники образовательного процесса.
В научных характеристиках дистанционного обучения $[7 ; 10 ; 11]$ указывается, что самая основная сложность заключалась в том, что переход на дистанционный формат обучения при отсутствии опыта использования образовательных онлайн-платформ, вебинаров и онлайн-курсов в рамках обучения у тренеров и у обучаемых застал и тех и других врасплох.

Тревожной выглядит и низкая оценка квалификации тренеров в области использования цифровых технологий со стороны обучающихся. Хотя такая оценка и является субъективной и не во всем может соответствовать реальности, тем не менее она демонстрирует отношение обучающихся к тренерам, как возможным экспертам или медиаторам в области цифровой активности. А это отношение определяется низким «цифровым» авторитетом тренеров в глазах обучающихся.

В результате такой стереотип может, как указывется в ряде источников [5; 13; 15], мешать обучаемым следовать за своими педагогами в условиях дистанционного обучения, способствовать недоверию к решениям обучающего по выбору цифровых инструментов, низкой оценке его цифровой компетентности и обесцениванию содержания его работы из-за отсутствия соответствующей ожиданиям цифровой представленности учебного материала. С другой стороны, учащиеся могут демонстрировать свою большую включенность в образовательный процесс, когда тренер выступает в качестве инноватора в использовании цифровых устройств: работает в новых для обучающихся цифровых форматах, использует знакомые учащимся онлайн-платформы для реализации образовательных задач, применяет широкий репертуар цифровых инструментов.

Определенное недоверие к процессу дистанционного обучения сформировали существующие у обучения специалистов в области управления персоналом представления о недостаточной цифровой квалификации педагогов. Такая установка со стороны обучения специалистов в области управления персоналом затрудняет ведение конструктивного диалога для эффективного и комфортного, насколько это было возможно в условиях форс-мажора, процесса дистанционного обучения.

Одним из путей решения проблем дистанционного обучения является задача обеспечения успешности проекта.

Использование известных компонентов дистанционного обучения основано на соответствующих подходах, вытекающих из приведенного выше характера воздействием информационных технологий на функционирование дистанционной образовательной среды, что предполагает и необходимость учета принципов безопасности и оптимизации обучающей среды. 
Итак, влияние цифровизации на формирование основ дистанционного обучения осуществляется посредством созданный ею следующих иструментов: электронные дневники, интерактивные доски, качественные видеоматериалы, обучающие платформы, другие сервисы (справочники, викепедия и т.п.).

К структуре функционирования системы дистанционного обучения мы отнесли:

- стратегии по взаимодействию тренеров с обучающими;

- систему организацию дистанционной образовательной среды;

- онлайн-технологии и основанные на них формы обучения;

- систему нейтрализации рисков и угроз дистанционного обучения.

- Модель взаимодействию тренеров с обучающими может выглядеть следующим образом:

— обучающий прослушивает лекцию тренера;
- изучает рекомендованную тренером дополнительную литературу, в том числе и из интернета;

- обсудить интересующую информацию с окружающими, в том числе и в интернета;

- находит в интернете, на сайтах и форумах людей, которых также интересует затронутая тема, чтобы поделиться информацией с ними и получить отклики (мнения).

- через обратную связь сообщает тренеру о степени усвоения учебного материала, выполненных заданиях и контрольных формах обучения.

Представляется, что такая форма обучения является более эффективной, чем традиционные занятия в аудитории, поскольку имеется выбор и предпочтения по взаимодействию участников образовательного процесса с цифровым продуктом, где уровень их активности в рамках дистанционной образовательной среды является показателем качества по предметному циклу.

\section{ЛИТЕРАТУРА}

1. Абрамовский А.Л. Дистанционное образование на современном этапе развития российского высшего образования: Дисс. .... канд. социол. наук. - Тюмень, 2014. 203 c.

2. Александрова Л.Н. Формирование готовности учителя к применению информационно-коммуникационных технологий в непрерывном профессиональном образовании: в процессе межкурсовой подготовки: Автореф. дис. ... канд. пед. наук. - Елец. 2016. 24 с.

3. Андреев А.А., Солдаткин В.И. Дистанционное обучение и дистанционные образовательные технологии // Cloud of science. 2013. № 1. C. 14-20.

4. Ахметова Д.З. Инклюзивный подход к психолого-педагогическому сопровождению обучения с применением дистанционных образовательных технологий; Ин-т экономики, управления и права. - Казань: Познание, 2014. 63 с.

5. Гайсина С.В. Цифровая грамотность и цифровая образовательная среда школы [Электронный ресурс] Режим доступа: hhtp://spbappo.ru.

6. Жданова Е.Г. Педагогические условия формирования умений самостоятельной деятельности студентов образовательных учреждений СПО средствами дистанционного обучения: Дисс. ...канд. пед. наук. - Воронеж, 2007. 199 с.

7. Починалина Л.Н. Педагогическое обеспечение самостоятельной работы студентов ВУЗа в условиях дистанционного обучения: Дисс. ....канд. пед. наук. М. 2007. 163 c.

8. Реан А.А. Психология и психодиагностика личности. Теория, методы исследования, практикум: арсенал практического психолога. - СПб: ПраймЕврознак. 2006. 255 c.

9. Скворцов А.А. Педагогические условия дистанционного обучения школьника в наукоемкой образовательной среде: Дисс. канд. пед. наук. - Тамбов. 2015.240 C.

10. Стариков С.А. Обучение педагогическим дисциплинам студентов вуза на основе дистанционных технологий: Дисс. ....канд. пед. наук. - Екатеринбург, 2007.212 C.

11. Стратегия дистанционного образования [Электронный ресурс] Режим доступа: https://swsu.ru/sbornik-statey/strategy-of-distance-education.php.

12. Теркулова И.Н. Цифровая среда как педагогическое условие позитивной социализации обучающихся во франкоговорящих странах (Франция, Канада): Автореф. дисс. ... канд. пед. наук. - М., 2019. 27 с.

13. Тимофеева Н.М. Цифровая грамотность как компонент жизненных навыков // Психология, социология и педагогика. 2015 . № 7 (46). С. $26-27$.

14. Чефранова А.О. Дистанционное обучение физике в школе и вузе на основе предметной информационно-образовательной среды: Автореф. дисс. ... докт. пед. наук. - М. 2006. 42 c.

15. Шариков А.В. 0 четырехкомпонентной модели цифровой грамотности // Журнал исследований социальной политики, 2016. Т. 14. № 1. С. 87-98.

(c) Зуев Иван Анатольевич (ivanzuev2010@mail.ru).

Журнал «Современная наука: актуальные проблемы теории и практики» 